\title{
O lúdico no ensino de ciências: uma revisão na Revista Brasileira de Pesquisa em Educação em Ciências
}

\author{
Playful in science teaching: a literature review in the Brazilian \\ Journal of Science Education Research
}

\author{
Adriana Ramos Pinheiro (adriana.pinheiro@ifrj.edu.br) \\ (Instituto Federal do Rio de Janeiro (IFRJ) \\ Sheila Pressentin Cardoso (shepressentin@gmail.com) \\ (Instituto Federal do Rio de Janeiro (IFRJ)
}

\begin{abstract}
Resumo: O artigo apresenta uma revisão de literatura com o objetivo de identificar como o lúdico vem sendo desenvolvido em pesquisas na área de educação em ciências, por meio da análise de artigos publicados na Revista Brasileira de Pesquisa em Educação em Ciências entre os anos de 2001 e 2018. Houve um levantamento e seleção das produções disponíveis no portal da revista, a partir de descritores correlatos ao tema da pesquisa. A análise do material ocorreu por meio da leitura do título, palavras-chave, resumo e, quando necessário, do texto na íntegra dos trabalhos selecionados. Com base na sistematização dos dados bibliográficos e pedagógicos os trabalhos foram organizados em 4 categorias de análise: aspectos gerais, aspectos pedagógicos, modalidade do estudo e tipo de atividade lúdica. As informações obtidas revelaram um panorama das pesquisas publicadas na revista e sugerem que o lúdico é pouco explorado como objeto de estudo em pesquisas na área de educação em ciências, indicando que a temática ainda possui potencial de crescimento em atividades de ensino e pesquisa.
\end{abstract}

Palavras-chave: recurso didático; ensino; pesquisa.

Abstract: The article presents a literature review with the purpose of identifying how the playful has been developed in research in the area of science education, through the analysis of articles published in the Brazilian Journal of Research in Science Education between 2001 and 2018. There was a survey and selection of the productions available on the magazine portal, using descriptors related to the search theme. The analysis of the material took place by reading the title, keywords, abstract and, when necessary, the full text of the selected works. Based on the information obtained from the systematization of bibliographical and pedagogical data, the works were organized into four categories of analysis: general aspects, pedagogical aspects, study modality and type of playful activity. The data obtained revealed an overview of the published research and suggest that the playful is little explored as an object of study in researches in the area of science education, indicating that the theme still has a great potential for growth in teaching and researches activities.

Keywords: $\quad$ didactic $\quad$ resource; teaching; research. 


\section{INTRODUÇÃO}

O mundo contemporâneo é mutável, especialmente no tocante as atividades diretamente ligadas aos processos científicos e tecnológicos. Em virtude disso é imprescindível que os indivíduos possuam um grau de dinamismo intelectual que os possibilite acompanhar os avanços da ciência e tecnologia.

A partir da premissa de que a escola é um dos principais locais de formação do ser humano, referenda-se a ela a responsabilidade de formar não só profissionais aptos para lidar com a dinâmica de nossa sociedade tecnológica, mas também cidadãos capazes de compreender os princípios que regem esta sociedade democrática. Portanto, é fundamental que a escola se modernize e se adeque aos padrões e às mudanças científico-tecnológicas pelas quais a sociedade é constantemente submetida (PINHEIRO; SILVEIRA; BAZZO， 2007; ARAÚJO; SILVA， 2012; KRAUSE; FELBER; VENQUIARUTO, 2018).

Nosso sistema de ensino tem seus alicerces galgados nos princípios expressos pela Lei de Diretrizes e Bases da Educação - LDB (BRASIL, 1996), referência legal para as posteriores reformulações propostas e referendadas na Base Nacional Comum Curricular (BNCC). De acordo com a BNCC (BRASIL, 2018), estabelece-se que os objetivos do ensino são:

O desenvolvimento de competências para aprender a aprender, saber lidar com a informação cada vez mais disponível, atuar com discernimento e responsabilidade nos contextos das culturas digitais, aplicar conhecimentos para resolver problemas, ter autonomia para tomar decisões, ser proativo para identificar os dados de uma situação e buscar soluções, conviver e aprender com as diferenças e as diversidades (BRASIL, 2018, p. 14).

Em outras palavras, o papel da escola é o de formar indivíduos autônomos que apresentem condições de aprender continuamente e acompanhar as mudanças de nossa sociedade tecnológica, e que sejam capazes de viver em sociedade exercendo sua cidadania.

Freire $(2010,2011)$ nos faz refletir sobre o papel do educador e do educando nesta conjuntura. Se por um lado o educador passa a ter o papel de "problematizador", 
encorajando o educando a desenvolver hipóteses, testar suas ideias e a dos outros, fazer conexões entre áreas de conteúdos, explorar problemas e questões de relevância pessoal já existentes ou emergentes, por outro lado o educando passa a ser envolvido em seu próprio processo de aprendizagem, tornando-se um sujeito ativo e não mais passivo como outrora. Para que isto ocorra faz-se necessária a formulação de práticas educativas que propiciem uma atmosfera de ensino agradável e que motivem o educando estimulando-o a aprender e, acima de tudo, participar ativamente de seu processo de aprendizagem.

Soares (2015) menciona que levar o lúdico para a sala de aula é uma alternativa plausível que pode ser usada pelos educadores como forma de despertar o interesse dos discentes e motivá-los de formas diversas, de modo a tirá-los de uma atitude passiva em sala de aula e aproximá-los do professor. Segundo o autor, as atividades lúdicas são valiosas no processo de apropriação do conhecimento, pois permitem o desenvolvimento de competências no âmbito da comunicação, das relações interpessoais, da liderança e do trabalho em equipe, utilizando a relação entre cooperação e competição em um contexto formativo. Em virtude disto diversas áreas, como por exemplo a pedagogia, a matemática e as ciências, se apropriam com frequência da utilização do lúdico na abordagem de seus conceitos.

As atividades lúdicas não podem ser empregadas como um mero recurso, sem que se tenha cuidado com aspectos pedagógicos que envolvem sua utilização, sendo necessário que o contexto das aulas seja modificado pois a simples aceitação do lúdico não garante uma mudança na postura pedagógica do professor (CUNHA, 2012). Fialho (2013) argumenta que o trabalho com o lúdico é uma opção diferenciada que pode ser empregada de diversas formas e em vários momentos de ensino. No processo de aprendizagem representa uma técnica facilitadora, pois auxilia os estudantes na elaboração de conceitos, na criatividade, no espírito de cooperação e competição, contribuindo com o desenvolvimento intelectual, social e afetivo.

Messeder Neto (2016) ressalta a relevância que a aplicação do lúdico possui no ensino de conteúdos científicos, mas atenta para o fato de que o educador, ao inserir uma atividade lúdica em sala de aula, precisa estar consciente de que seu fim é fazer o aluno migrar do interesse pela atividade para o estudo, pois ao fim do processo a 
motivação deve ser pelo conteúdo abordado e não pela atividade lúdica que o introduziu.

Dada a importância e as possibilidades da utilização de atividades lúdicas no ensino, este artigo apresenta uma revisão de literatura com o objetivo de identificar como o lúdico vem sendo tratado nos estudos desenvolvidos na área de educação em ciências, por meio da análise de artigos publicados na Revista Brasileira de Pesquisa em Educação em Ciências (RBPEC).

\section{METODOLOGIA}

A pesquisa foi do tipo revisão de literatura, que se caracteriza por identificar a produção existente relacionada a um determinado tema, para auxiliar na formulação de perguntas e indicar pontos polêmicos e lacunas no conhecimento relacionado ao assunto que se pretende estudar (CRESWELL, 2014). De acordo com Massoni e Moreira (2017), a revisão de literatura é um dos itens fundamentais na pesquisa em educação. Neste contexto buscou-se identificar como o lúdico vem sendo tratado nas pesquisas em educação em ciências no Brasil, a partir dos trabalhos publicados na RBPEC entre os anos de 2001 e 2018.

A RBPEC foi criada em 2001, sendo regularmente publicada com periodicidade quadrimestral, passando para modalidade de fluxo contínuo em 2019. A revista tem como objetivo disseminar resultados e reflexões advindos de investigações conduzidas em educação em ciências, de forma a contribuir com a consolidação da área, a formação de pesquisadores, e a produção de conhecimentos em educação em ciências. A RBPEC está vinculada à Associação Brasileira de Pesquisa em Educação em Ciências (ABRAPEC), que possui associados nas diversas áreas das ciências da natureza, podendo ser considerada a associação que melhor representa os pesquisadores da área de educação em ciências no Brasil (EIRAS; MENEZES; FLÔR, 2018), motivo pelo qual foi escolhida para o estudo sistemático desenvolvido neste trabalho. 
A coleta dos dados ocorreu a partir do levantamento e seleção das produções, no portal da RBPEC ${ }^{1}$, tendo como critério descritores correlatos ao tema abordado, dentre eles: atividade lúdica, lúdico, ludicidade, brincar, brinquedo, brincadeira, interessante, motivador, criatividade, criativo, atraente, interessante, jogo didático/educativo/eletrônico/virtual, games, simulação, objeto virtual de aprendizagem (OVA), software educativo, multimídia, teatro, música, museu, cinema, filme, série, novela, fotonovela, vídeo, poema, história em quadrinhos, trilha, gincana, júri e suas variações no plural além dos cruzamentos com os termos educação, ensino e com as expressões e/para o/no ensino de ciências.

A análise do material envolveu a leitura do título, palavras-chave, resumo e, quando necessário, do texto na íntegra. Com base na sistematização dos dados bibliográficos e pedagógicos os trabalhos foram avaliados conforme as seguintes categorias de análise: aspectos gerais, aspectos pedagógicos, modalidade do estudo e tipo de atividade lúdica. As duas primeiras categorias foram definidas a priori com base nos descritores estabelecidos por Megid Neto (1999), e a terceira e a quarta categorias emergiram da leitura e análise dos trabalhos selecionados.

A primeira categoria, aspectos gerais, relaciona os dados bibliográficos dos trabalhos que envolvem informações formais de uma produção, tais como número de artigos, edição, ano de publicação, região e unidade federativa de origem. A relação entre esses dados permite um diagnóstico do crescimento da área, e a partir da análise da relação entre a região e a unidade federativa dos trabalhos é possível mapear sua distribuição e disseminação no país (SOARES; GARCEZ, 2017).

Na segunda categoria, aspectos pedagógicos, foram analisadas questões referentes às propostas pedagógicas apresentadas, sendo explorados o nível de ensino e o componente curricular para os quais os trabalhos se direcionaram. Esses dados permitem verificar aspectos priorizados nas propostas pedagógicas, e aqueles pouco desenvolvidos ou mesmo não explorados, possibilitando visualizar como tem ocorrido a utilização do lúdico na área de pesquisa em educação em ciências (SOARES; GARCEZ, 2017).

\footnotetext{
${ }^{1}$ https://seer.ufmg.br/index.php/rbpec.
} 
A terceira categoria, modalidade de estudo, destaca o foco da investigação, com a quarta categoria, tipo de atividade lúdica, abordando as atividades propostas e aplicadas nos trabalhos selecionados.

\section{RESULTADOS E DISCUSSÃO}

No período compreendido entre 2001 e 2018 a RBPEC publicou um total de 473 artigos, distribuídos em 18 volumes, como apresentado no Quadro 1.

Quadro 1: Distribuição quantitativa de artigos publicados nos 18 volumes da RBPEC.

\begin{tabular}{|c|c|c|c|c|c|c|}
\hline Volume & Ano & N.1 & $\mathbf{N . 2}$ & $\mathbf{N . 3}$ & $\begin{array}{c}\text { Total de artigos } \\
\text { publicados }\end{array}$ & $\begin{array}{c}\text { Total de artigos com } \\
\text { temática lúdica }\end{array}$ \\
\hline 1 & 2001 & 12 & 12 & 12 & 36 & 1 \\
\hline 2 & 2002 & 6 & 8 & 6 & 20 & 0 \\
\hline 3 & 2003 & 8 & 4 & 4 & 16 & 1 \\
\hline 4 & 2004 & 8 & 8 & 8 & 24 & 0 \\
\hline 5 & 2005 & 6 & 4 & 5 & 15 & 1 \\
\hline 6 & 2006 & 4 & 4 & 4 & 12 & 1 \\
\hline 7 & 2007 & 4 & 4 & 4 & 12 & 3 \\
\hline 8 & 2008 & 6 & 6 & 6 & 18 & 0 \\
\hline 9 & 2009 & 7 & 6 & 7 & 20 & 6 \\
\hline 10 & 2010 & 8 & 7 & 7 & 22 & 0 \\
\hline 11 & 2011 & 10 & 10 & 10 & 30 & 1 \\
\hline 12 & 2012 & 10 & 10 & 10 & 30 & 2 \\
\hline 13 & 2013 & 10 & 10 & 9 & 29 & 1 \\
\hline 14 & 2014 & 10 & 26 & 8 & 44 & 1 \\
\hline 15 & 2015 & 10 & 10 & 10 & 30 & 2 \\
\hline 16 & 2016 & 10 & 12 & 16 & 38 & $\mathbf{2 7}$ \\
\hline 17 & 2017 & 13 & 14 & 13 & 40 & 37 \\
\hline 18 & 2018 & 14 & 12 & 11 & $\mathbf{4 3}$ & 2 \\
\hline
\end{tabular}

Fonte: elaborado pelas autoras.

Com os descritores predefinidos foram identificados 27 artigos relacionados à temática lúdico, o que corresponde a cerca de 5,60\% do total de artigos publicados no período. A análise de tal dado sugere que o lúdico é pouco explorado como objeto de estudo na área de pesquisa em educação em ciências. A relação dos trabalhos selecionados, os componentes curriculares abordados, o nível de ensino envolvido e o tipo de atividade lúdica utilizada são apresentados no Anexo deste artigo. 
A primeira categoria analisada foi aspectos gerais, onde observou-se a ausência de pesquisas publicadas sobre o tema nos anos de 2002, 2004, 2005, 2009 e 2012 (Quadro 1). Os anos de 2011 e 2014 se destacam na apresentação de pesquisas envolvendo o lúdico com, respectivamente, 6 e 4 trabalhos publicados em cada ano. Outro ponto analisado diz respeito a distribuição dos artigos por região e unidade federativa (Quadro 2). As unidades federativas que mais se destacam, em termo de publicação sobre atividades lúdicas, são o Rio de Janeiro (22,2\%), Minas Gerais (14,8\%), São Paulo $(14,8 \%)$ e Rio Grande do Sul (14,8\%). Verifica-se uma concentração dessas pesquisas na região sudeste $(55,5 \%)$, seguida pelas regiões sul $(18,5 \%)$, nordeste e centro-oeste (ambas com 11,11\%), com a região norte apresentando o menor número de trabalhos $(3,70 \%)$.

Quadro 2: Distribuição quantitativa dos artigos por região e unidade federativa de origem.

\begin{tabular}{|c|c|c|c|}
\hline Região & Unidade Federativa & Total de artigos & Percentual (\%) \\
\hline \multirow{3}{*}{ Sudeste } & Espírito Santo (ES) & 1 & 3,70 \\
\cline { 2 - 4 } & Minas Gerais (MG) & 4 & 14,8 \\
\cline { 2 - 4 } & Rio de Janeiro (RJ) & 6 & 22,2 \\
\cline { 2 - 4 } & São Paulo (SP) & 4 & 14,8 \\
\hline \multirow{2}{*}{ Centro-Oeste } & Distrito Federal (DF) & 1 & 3,70 \\
\cline { 2 - 4 } & Goiás (GO) & 2 & 7,41 \\
\hline \multirow{2}{*}{ Sul } & Paraná (PR) & 1 & 3,70 \\
\cline { 2 - 4 } & Rio Grande do Sul (RS) & 4 & 14,8 \\
\hline \multirow{2}{*}{ Nordeste } & Bahia (BA) & 1 & 3,70 \\
\cline { 2 - 4 } & Pernambuco (PE) & 1 & 3,71 \\
\hline Norte & Rondônia (RO) & $\mathbf{2 7}$ & $\mathbf{1 0 0}$ \\
\hline & Total & & \\
\hline
\end{tabular}

Fonte: elaborado pelas autoras.

Essas informações sugerem que nas regiões sul e sudeste existem grupos que se dedicam à pesquisa do lúdico na educação em ciências. Na análise do currículo Lattes dos autores identificou-se um total de 10 grupos de pesquisa nessas duas regiões, estando 8 na região sudeste e 2 na região sul.

A segunda categoria analisada foi aspectos pedagógicos, na qual buscou-se os níveis de ensino para os quais os trabalhos foram direcionados, e entender como estão distribuídos em relação aos componentes curriculares da área de ciências. O Quadro 3 apresenta a distribuição quantitativa dos artigos por nível de ensino, destacando que alguns trabalhos trazem uma abordagem que pode ser voltada para mais de um nível de 
ensino, logo, foram computados mais de uma vez na elaboração do referido quadro. $\mathrm{O}$ mesmo procedimento foi realizado nas demais avaliações apresentadas ao longo do texto.

Quadro 3: Distribuição quantitativa dos trabalhos selecionados por níveis de ensino e componente (s) curricular (es) abordado (s).

\begin{tabular}{|c|c|c|c|c|c|}
\hline $\begin{array}{c}\text { Nível } \\
\text { de ensino }\end{array}$ & $\begin{array}{c}\text { Total de } \\
\text { artigos }\end{array}$ & Biologia & Física & Química & $\begin{array}{c}\text { Outro } \\
\text { componente } \\
\text { curricular }\end{array}$ \\
\hline Educação infantil & 1 & 0 & 0 & 1 & 0 \\
\hline Ensino fundamental & 8 & 4 & 3 & 1 & 6 \\
\hline Ensino médio & 13 & 5 & 5 & 4 & 4 \\
\hline Ensino técnico & 2 & 0 & 1 & 0 & 1 \\
\hline $\begin{array}{c}\text { Educação de jovens e } \\
\text { adultos (EJA) }\end{array}$ & 3 & 1 & 0 & 3 & 0 \\
\hline Formação de professores & 1 & 0 & 0 & 0 & 1 \\
\hline $\begin{array}{c}\text { Ensino superior e pós- } \\
\text { graduação }\end{array}$ & 3 & 0 & 0 & 2 & 1 \\
\hline Total & $\mathbf{3 1}$ & $\mathbf{1 0}$ & $\mathbf{9}$ & $\mathbf{1 1}$ & $\mathbf{1 3}$ \\
\hline
\end{tabular}

Fonte: elaborado pelas autoras.

Observa-se que o número de trabalhos voltados para a educação infantil é baixo (1). Isso nos leva a refletir, pois o artigo nono das Diretrizes Curriculares Nacionais para a Educação Infantil - DCNEI (BRASIL, 2009) define que os eixos estruturantes das práticas pedagógicas dessa etapa da educação básica são as interações e a brincadeira, experiências nas quais as crianças podem construir e apropriar-se de conhecimentos por meio de suas ações e interações com seus pares e com os adultos, o que possibilita aprendizagem, desenvolvimento e socialização. Ademais, de acordo com a BNCC:

\begin{abstract}
A educação infantil precisa promover experiências nas quais as crianças possam fazer observações, manipular objetos, investigar e explorar seu entorno, levantar hipóteses e consultar fontes de informação para buscar respostas às suas curiosidades e indagações. Assim, a instituição escolar está criando oportunidades para que as crianças ampliem seus conhecimentos do mundo físico e sociocultural e possam utilizá-los em seu cotidiano (BRASIL, 2018, p. 43).
\end{abstract}

Pode-se inferir que na educação infantil muitos dos professores que lecionam ciências têm formação em pedagogia e, consequentemente, pouco ou nenhum vínculo com a ABRAPEC. Logo, os trabalhos voltados para este nível de ensino podem estar sendo publicados em outras revistas da área de educação. Ademais, Francisco, 
Alexandrino e Queiroz (2015) alertam sobre o baixo número de trabalhos voltados para a educação infantil, relacionando esta carência ao fato de a formação dos professores deste nível de ensino ser em pedagogia, o que acaba por implicar na falta de conhecimentos de conteúdos específicos de ciências, dificultando, portanto, sua abordagem.

Longhini (2008) destaca que uma das especificidades do ensino de ciências na educação infantil é contar com professores com formação em pedagogia, geralmente responsáveis também pelo ensino de outras áreas do conhecimento, chamando atenção para o fato de que grande parte destes professores possui deficiências nos conteúdos científicos que necessitam ensinar, o que gera insegurança e causa dificuldade para inserirem atividades diferenciadas das tradicionalmente realizadas.

Outro ponto interessante é o predomínio de trabalhos voltados para o ensino fundamental (8) e médio (13). Os artigos publicados pela RBPEC são direcionados a professores e pesquisadores da área de educação em ciências sendo, portanto, uma revista intimamente relacionada com a educação básica, o que pode explicar a maioria dos artigos voltados para os níveis de ensino mencionados. Em seu artigo, Silva e Amaral (2015) indicam que os níveis privilegiados nas pesquisas em ensino de ciências são o ensino fundamental, sobretudo nos anos finais, e o ensino médio, apontando que essa tendência está intimamente relacionada ao fato da maior parte dos autores terem experiência docente nestes níveis de ensino e, por conta disto, buscarem investigar problemas provenientes de suas próprias práticas, não tendo interesse em direcionar suas pesquisas para outros níveis de ensino. Alves-Mazzotti (2001) coloca de forma pertinente que muitos pesquisadores, especialmente os alunos de mestrado, tendem a permanecer "colados" em suas próprias práticas e delas acabam derivando seus trabalhos de pesquisa e a elas retornam com aplicações imediatas dos resultados obtidos. Neste contexto, a autora pondera que:

Não se está aqui criticando o fato de se desenvolver uma pesquisa a partir de dificuldades encontradas na prática. Na realidade, muitas pesquisas pecam exatamente por seu completo distanciamento dos problemas com que se defrontam os professores no cotidiano da sala de aula. Mas se o pesquisador permanece no nível de sua prática específica e de seus interesses individuais, sem uma tentativa de teorização que permita estender suas reflexões a outras situações, pouco ou nada contribui para a construção de conhecimentos relevantes (ALVES-MAZZOTTI, 2001, p. 41). 
A análise dos dados presentes ao Quadro 3 sugere que não há uma preocupação ou interesse dos professores que atuam no ensino técnico, na educação de jovens e adultos (EJA), na formação de professores, na graduação e pós-graduação em inserir o lúdico como estratégia de ensino em suas pesquisas, tendo em vista a pequena quantidade de trabalhos produzidos.

Embora a disciplina de ciências seja específica da educação infantil e do ensino fundamental, ela não se restringe a essas modalidades e níveis de ensino. Neste contexto, seria interessante incentivar pesquisas voltadas para espaços pouco explorados, como por exemplo a educação especial, a educação do campo, a educação escolar indígena, a educação escolar quilombola e a educação à distância, assim como incentivar pesquisas voltadas para a educação de jovens e adultos.

O Quadro 3 também apresenta como os artigos estão distribuídos em relação aos componentes curriculares da área de ciências (biologia, física e química). Vale destacar que alguns trabalhos incluem componentes curriculares fora da área de ciências, sendo agrupados na coluna "outro componente curricular". Parte deles possui uma proposta diferenciada trazendo atividades que envolvem: (i) conteúdos diferentes, da mesma ou de outras disciplinas, abordados simultaneamente; (ii) propostas de se trabalhar de forma transdisciplinar ou interdisciplinar e (iii) propostas envolvendo o trabalho com temas transversais.

Percebe-se um maior número de trabalhos relacionados a componentes curriculares fora da área de ciências da natureza, com um total de 13 trabalhos concentrados nos ensinos fundamental e médio. Entre os componentes curriculares da área de ciências há uma distribuição equilibrada, com 11 trabalhos voltados para a química, 10 para a biologia e 9 para a física. Em relação a esses componentes curriculares, os trabalhos se concentram nos ensinos fundamental e médio, com um maior número envolvendo a biologia (5), física (5) e química (4) destinados a alunos do ensino médio. Esse fato pode estar relacionado com os objetivos gerais dos cursos de licenciatura em biologia, física e química que, em sua maioria, priorizam a formação de docentes para esse nível de ensino.

Apesar disso, o número de trabalhos de biologia (4) e física (3) destinados ao ensino fundamental é significativo. No que diz respeito à área de biologia este 
quantitativo pode estar relacionado com os docentes de ciências que são, em sua maioria, licenciados em biologia (CHAVES; SHELLARD, 2005). Já em relação à área de física os valores sugerem uma mudança de interesse dos graduados em física, que parecem estar olhando de forma diferenciada para o ensino fundamental, momento da educação básica onde os alunos começam a trabalhar conteúdos de física, o que pode se configurar em um campo de pesquisa em ascensão.

A terceira categoria analisada foi modalidade do estudo, com destaque para o foco da investigação realizada. Sob esse aspecto os trabalhos foram organizados em subcategorias, a saber: proposta de atividade lúdica, teórico de ensino elou aprendizagem, ou revisão de literatura.

Os artigos classificados na subcategoria proposta de atividade lúdica, no total de 24, possuem como principais objetivos: (i) aplicar atividades lúdicas com posterior avaliação da proposta ou da aprendizagem proporcionada; (ii) divulgar e/ou disseminar a ciência no meio escolar ou para a comunidade; (iii) apresentar o lúdico como estratégia didática para a formação inicial ou continuada do professor de ciências, ou sua utilização como atividade de ensino para o licenciando; (iv) apresentar propostas para o ensino de ciências por meio da descrição de atividades lúdicas que apresentam sua estrutura, objetivo, regras e sugestões para sua confecção e aplicação e (v) fazer questionamentos acerca do significado das atividades lúdicas para os alunos nos diversos níveis de ensino.

Já na subcategoria teórico de ensino elou aprendizagem estão os trabalhos que fizeram uso de conceitos de teóricos da educação para discutir o lúdico, contribuindo para que se forme um arcabouço teórico e metodológico para o campo de pesquisa do lúdico na área de educação em ciências. Nesta subcategoria foi identificado apenas 1 artigo, onde a autora analisa a pipa à luz dos quatro significados de mediação sociotécnica apontados por Bruno Latour (RBPEC 9, Anexo). Enquanto na terceira subcategoria, revisão de literatura, os trabalhos apresentam um caráter teórico, contudo o objetivo foi analisar produções publicadas com o tema lúdico, sendo identificados 2 artigos com essas características (RBPEC 25 e RBPEC 26, Anexo).

Nesta categoria, a maior parte dos trabalhos (88,9\%) foi classificada na subcategoria proposta de atividade lúdica, indicando que as pesquisas se concentram na 
aplicação ou divulgação do lúdico como tendência no ensino de ciências. Muitos desses trabalhos carecem de um referencial teórico e metodológico mais encorpado, de modo a permitir que o tema lúdico se consolide, de fato, na área de pesquisa em educação em ciências. Em virtude disto, pode ficar a ideia de que o lúdico, por si só, é responsável pelo processo de aprendizagem de conceitos científicos.

A quarta categoria a ser analisada foi tipo de atividade lúdica, com o Quadro 4 apresentando a distribuição quantitativa dos artigos conforme o tipo de atividade lúdica proposta, e a subcategoria na qual está agrupada por similaridade.

Quadro 4: Distribuição quantitativa dos trabalhos selecionados por tipo de atividade lúdica.

\begin{tabular}{|c|c|c|}
\hline Subcategoria & Tipo de atividade lúdica & $\begin{array}{l}\text { Total de } \\
\text { artigos }\end{array}$ \\
\hline $\mathrm{I}$ & $\begin{array}{l}\text { Vídeo, filme, história infantil, história em quadrinhos } \\
\text { e mural }\end{array}$ & 7 \\
\hline II & $\begin{array}{l}\text { Software, hipermídia, objeto virtual de aprendizagem } \\
\text { (OVA) e microportal com recursos multimídia }\end{array}$ & 5 \\
\hline III & $\begin{array}{l}\text { Museu, galeria de arte, centro de divulgação } \\
\text { científica e trilha }\end{array}$ & 5 \\
\hline IV & Jogo & 7 \\
\hline $\mathrm{V}$ & Experimentação & 5 \\
\hline VI & Teatro & 1 \\
\hline VII & Brinquedo e brincadeira & 5 \\
\hline Total & & 35 \\
\hline
\end{tabular}

Fonte: elaborado pelas autoras.

As subcategorias I e IV se destacam por agruparem atividades lúdicas empregadas em um maior número de trabalhos. Na subcategoria I utilizam a linguagem mista para que os alunos se comuniquem, expressem, acessem, partilhem e disseminem informações, experiências, ideias e sentimentos em diferentes contextos. Sob este aspecto, a necessidade de se estudar o comportamento humano, enquanto fenômeno histórico e socialmente determinado, fez com que Vigotski e colaboradores se dedicassem a estudos que pudessem atestar a ideia de que o pensamento adulto é culturalmente mediado, e que a linguagem é o meio principal desta mediação (REGO, 2014).

Portanto, a linguagem possui um papel crucial na elaboração de conceitos e, sendo assim, é um dos principais recursos dentro dos processos de aquisição de novos conhecimentos. Porém, a linguagem não é estável, principalmente no que concerne aos 
conhecimentos científicos onde existem várias formas de representação de uma mesma situação real. Neste cenário, fazer uso de recursos didáticos que utilizem diferentes linguagens é interessante, pois facilitam o processo de ensino e de aprendizagem de ciências.

Na subcategoria IV tem-se os jogos utilizados como recurso didático. Cavalcanti e Soares (2010) entendem que o jogo propicia a experiência do êxito, pois é significativo e, sendo assim, possibilita a autodescoberta, a assimilação e a integração com o ambiente mediante relações e vivências. Neste contexto é possível melhorar a autoestima do educando, a relação aluno-aluno e aluno-professor, além de trazer significado para o educando e prazer em estar aprendendo determinado conteúdo.

Bomtempo (1999) afirma que brincando a criança desenvolve capacidades físicas, verbais e intelectuais que potencializam sua capacidade de se comunicar. Sob este aspecto o jogo acaba sendo um fator de comunicação mais amplo do que a própria linguagem, pois proporciona o diálogo entre pessoas de culturas diferentes. Os autores apontam que a linguagem científica do docente é difícil de ser compreendida durante as aulas expositivas e, portanto, os jogos podem proporcionar discussões em que ocorre a interação entre as linguagens do docente e de seus educandos, o que facilita o estabelecimento de um significado comum a ambos, contribuindo para uma aprendizagem significativa dos conceitos científicos trabalhados no jogo.

As subcategorias II, III, V e VII agrupam atividades lúdicas que também foram utilizadas em um número expressivo de trabalhos. A subcategoria II apresenta atividades que utilizam a linguagem digital e são, mais especificamente, chamadas de tecnologias digitais de informação e comunicação (TDIC's). Em virtude da multiplicação das TDIC's, e do crescente acesso a computadores, telefones celulares, tablets e afins, os discentes estão dinamicamente inseridos na cultura digital (BRASIL, 2018). Segundo a BNCC, são competências gerais da educação básica:

Compreender, utilizar e criar tecnologias digitais de informação e comunicação de forma crítica, significativa, reflexiva e ética nas diversas práticas sociais, incluindo as escolares, para se comunicar, acessar e disseminar informações, produzir conhecimentos, resolver problemas e exercer protagonismo e autoria na vida pessoal e coletiva (BRASIL, 2018, p. 9). 
Portanto, utilizar diferentes TIDC's como recurso didático no ensino de ciências para se comunicar, acessar e disseminar informações, favorece a aprendizagem de conceitos e auxilia na resolução de problemas das ciências da natureza de forma crítica, significativa, reflexiva e ética.

A subcategoria III engloba atividades desenvolvidas em espaços não formais de ensino. Para Schvingel et al. (2016) os processos de ensino e de aprendizagem acontecem durante toda a vida das pessoas por meio da educação, seja em espaços formais ou não formais. Muitos de nossos conhecimentos não são adquiridos, necessariamente, no ambiente escolar, e sim em espaços não formais.

Reis, Oliveira e Rizzatti (2019) afirmam que as práticas educativas em espaços não formais contribuem para que os discentes relacionem a teoria com a prática, contudo, ressaltam a importância do docente conhecer previamente o espaço não formal ao qual fará uso, para verificar o seu potencial de atingir os objetivos da aula planejada, evitando assim surpresas desagradáveis que possam comprometer seus objetivos pedagógicos ou mesmo causar danos físicos aos estudantes presentes.

Portanto, fomentar a educação não formal é interessante, pois propõe um processo de socialização dos indivíduos, capacitando-os a se tornarem cidadãos mais críticos, numa relação de abertura do conhecimento sobre o mundo e de exercício de cidadania.

$\mathrm{Na}$ subcategoria $\mathrm{V}$ a experimentação é proposta na complementação do ensino de ciências, sendo uma prática educativa interessante que estimula a criatividade dos educandos na resolução de problemas, permite que desenvolvam uma atitude científica, cria uma atmosfera agradável em sala de aula, e ajuda a promover a compreensão dos fundamentos científico-tecnológicos dos processos produtivos, relacionando a teoria com a prática no ensino da disciplina em questão (BRASIL, 1996).

Giordan (1999) cita que as atividades experimentais podem ser articuladas com atividades de ensino, sendo mais um instrumento de mediação entre o sujeito, seu mundo e o conhecimento científico. Para o autor, a elaboração do conhecimento científico apresenta-se dependente de uma abordagem experimental, não tanto pelos temas de seu objeto de estudo, os fenômenos naturais, mas fundamentalmente porque a organização desse conhecimento ocorre, preferencialmente, nos entremeios da investigação. 
Na subcategoria VII estão representados os brinquedos e brincadeiras. De acordo com a BNCC:

\begin{abstract}
A interação durante o brincar caracteriza o cotidiano da infância, trazendo consigo muitas aprendizagens e potenciais para o desenvolvimento integral das crianças. Ao observar as interações e a brincadeira entre as crianças e delas com os adultos, é possível identificar, por exemplo, a expressão dos afetos, a mediação das frustrações, a resolução de conflitos e a regulação das emoções (BRASIL, 2018, p. 37).
\end{abstract}

Vigotski (2007) afirma que o brinquedo não é o aspecto predominante da infância, mas é um fator muito importante do desenvolvimento, pois:

O brinquedo cria uma zona de desenvolvimento proximal da criança. No brinquedo, a criança sempre se comporta além do comportamento habitual de sua idade, além do seu comportamento diário; no brinquedo, é como se ela fosse maior do que é na realidade. Como no foco de uma lente de aumento, o brinquedo contém todas as tendências do desenvolvimento sob forma condensada, sendo, ele mesmo, uma grande fonte de desenvolvimento (VIGOTSKI, 2007, p. 122).

Refletindo sobre a questão percebe-se que o ato de brincar também mexe com a criatividade, o senso crítico e a capacidade de tomada de decisão do educando sendo, portanto, um dos principais meios de desenvolvimento cultural. Neste contexto, pesquisas que enfatizam o brinquedo como material motivador são fundamentais, pois brincar para a criança não é uma questão apenas de diversão, mas também de educação, socialização, construção e pleno desenvolvimento de suas potencialidades.

Já o teatro, presente na subcategoria VI, foi utilizado como atividade lúdica em somente um trabalho. Segundo Oliveira e Stoltz (2010) o uso do teatro na escola deve ser incentivado, pois motiva os alunos à aprendizagem e lhes permite construir seu próprio conhecimento.

O teatro usa a linguagem verbal e corporal, a memorização, a atenção, também a organização espacial. Todas exigem a interação social e fazem parte da cultura. Todas implicam a mobilização de aspectos cognitivos, afetivos, sociais e motores dos sujeitos; implicam ainda em aprendizagens, exercício repetitivo, construção de conhecimento (OLIVEIRA; STOLTZ, 2010, p. 86).

Observando o Quadro 4 percebe-se a variedade de atividades lúdicas que podem ser utilizadas como recurso didático no ensino de ciências. Apesar disso, a análise dos trabalhos selecionados revelou que não há uma preocupação em se usar um referencial teórico e metodológico que possa auxiliar no entendimento dos fatores envolvidos nos 
processos de ensino e de aprendizagem de conceitos científicos na aplicação dessas atividades em sala de aula. Isso pode ser interpretado como uma fragilidade das pesquisas e trabalhos da área, que deve ser superada através do incentivo a trabalhos de pesquisa voltados para a exploração e o desenvolvimento das potencialidades dessas atividades lúdicas.

\section{CONSIDERAÇÕES FINAIS}

Na revisão de literatura dos trabalhos publicados na RBPEC, entre os anos de 2001 e 2018, constatou-se a pequena porcentagem de artigos relacionados ao lúdico, sugerindo que a temática ainda é pouco explorada como objeto de estudo nas pesquisas na área de educação em ciências.

A análise dos vinte e sete trabalhos selecionados revelou uma concentração dessas pesquisas em algumas regiões e unidades da federação, com a presença de grupos de pesquisa abordando a utilização de atividades lúdicas no ensino de ciências e havendo, desta forma, um potencial para o desenvolvimento de pesquisas sobre o tema. Por outro lado, algumas unidades da federação possuem pequena porcentagem no total das pesquisas relacionadas ao lúdico, o que sugere a necessidade de um maior investimento, ou até mesmo a formação de grupos de pesquisa em educação em ciências nessas regiões.

Ocorre um predomínio de trabalhos voltados para os ensinos fundamental e médio, levando à impressão de que não existe uma preocupação ou interesse dos professores que atuam nos demais níveis de pesquisar e inserir o lúdico em suas estratégias de ensino. Torna-se necessário o incentivo a trabalhos de pesquisa voltados para esses níveis de ensino, bem como para a educação especial, a educação do campo, a educação escolar indígena, a educação escolar quilombola e a educação à distância.

A variedade de atividades lúdicas propostas como recurso didático para o ensino de ciências é um ponto a se destacar, com diferentes linguagens e formas de apresentar e discutir os temas abordados, revelando a riqueza de ações que podem ser desenvolvidas e que atendem a diferentes conteúdos e níveis de ensino. Percebe-se que a pesquisa do lúdico na educação em ciências representa uma importante linha de investigação sendo, 
portanto, importante incentivar propostas para explorar e desenvolver as potencialidades dessas atividades em sala de aula.

A carência de uma apresentação e discussão do emprego do lúdico com base em um referencial teórico e metodológico consistente ficou evidente, o que pode ser entendido como uma fragilidade das pesquisas da área, que dão maior importância à função lúdica do que à função educativa. Neste contexto, a área de educação em ciências carece de estudos dos fatores que envolvem os processos de ensino e de aprendizagem de conceitos científicos a partir de atividades lúdicas.

E, por fim, este trabalho procurou apresentar um panorama das pesquisas sobre o lúdico em educação em ciências no Brasil, a partir de uma revista de referência na área, visando contribuir para que pesquisadores e professores reflitam sobre as potencialidades do uso do lúdico no ensino de ciências, e se sintam encorajados a usar e divulgar a aplicação de atividades lúdicas como recurso didático em suas salas de aula.

\section{REFERÊNCIAS}

ALVES-MAZZOTTI, A. Relevância e aplicabilidade da pesquisa em educação. Cadernos de Pesquisa, n. 113, p. 39-50, 2001.

ARAÚJO, A. B.; SILVA, M. A. Ciência, tecnologia e sociedade; trabalho e educação: possibilidades de integração no currículo da educação profissional tecnológica. Revista Ensaio, Belo Horizonte, v. 14, n. 1, p. 99-112, 2012.

BRASIL. Ministério da Educação. Lei de Diretrizes e Bases da Educação Nacional: Lei nº 9394, Brasília, 1996.

BRASIL. Ministério da Educação. Diretrizes Curriculares Nacionais para a Educação Infantil. Resolução Conselho Nacional de Educação (CNE)/Câmara de Educação Básica (CEB) N5, Brasília: MEC, dez. 2009.

BRASIL. Ministério da Educação. Base Nacional Comum Curricular: Educação é a Base, Brasília: MEC, 2018.

BOMTEMPO, E. Brinquedo e educação: Na escola e no lar. Psicologia Escolar e Educacional, v. 3, n. 1, p. 61-69, 1999.

CAVALCANTI, E. L. D.; SOARES, M. H. F. B. O ludismo e avaliação da aprendizagem: possibilidades para o ensino de química. In: XV ENCONTRO 
NACIONAL DE ENSINO DE QUÍMICA. 21 a 24 de julho 2010, Brasília. Anais eletrônicos... Brasília, 2010.

CHAVES. A.; SHELLARD, R. C. Pensando o futuro: o desenvolvimento da física e sua inserção na vida pessoal e econômica do país. Sociedade Brasileira de Física, Comissão para a Física no Brasil, São Paulo, 2005.

CRESWELL, J. W. Investigação qualitativa e projeto de pesquisa. Porto Alegre: Penso, 2014.

CUNHA, M. B. Jogos no ensino de química: considerações teóricas para sua utilização em sala de aula. Química Nova na Escola, v. 34, n. 2, p. 92-98, 2012.

EIRAS, W. C. S.; MENEZES, P. H. D.; FLÔR, C. C. C. Brinquedos e brincadeiras na educação em ciências: um olhar para a literatura da área no período de 1997 a 2017. Revista Brasileira de Pesquisa em Educação em Ciências, v. 18, n. 1, p. 179-203, 2018.

FIALHO, N. N. Jogos no ensino de Química e Biologia. Curitiba: Intersaberes, 2013.

FRANCISCO, C. A.; ALEXANDRINO, D. M.; QUEIROZ, S. L. Análise de dissertações e teses sobre o ensino de química no Brasil: produção científica de programas de pós-graduação em destaque. Investigações em Ensino de Ciências, v. 20, n. 3, p. 21-60, 2015.

FREIRE, P. Pedagogia da autonomia: saberes necessários à prática educativa. Rio de Janeiro: Paz e Terra, 2010.

FREIRE. Pedagogia do oprimido. Rio de Janeiro: Paz e Terra, 2011.

GIORDAN, M. O papel da experimentação no ensino de ciências. Química Nova na Escola, v. 10, n. 10, p. 43-49, 1999.

KRAUSE, J.C.; FELBER, D.; VENQUIARUTO, L. D. O uso de jogos digitais como ferramenta de auxílio para o ensino de Física. Revista Insignare Scientia, v. 1, n. 2, p. $1-25,2018$.

LONGHINI, M. D. O conhecimento do conteúdo científico e a formação do professor das séries iniciais do ensino fundamental. Investigações em Ensino de Ciências, v. 13, n. 2, p. 241-253, 2008.

MASSONI, N. T.; MOREIRA, M.A. Pesquisa qualitativa em educação em ciências: projetos, entrevistas, questionários, teoria fundamentada, redação científica. São Paulo: Livraria da Física, 2017.

MEGID NETO, J. Tendências da pesquisa acadêmica sobre o ensino de ciências no nível fundamental. 1999. 238 f. Tese (Doutorado em Educação) - Universidade Estadual de Campinas, Campinas, 1999. 
MESSEDER NETO, H. S. O lúdico no ensino de Química na perspectiva históricocultural: Além do espetáculo, além da aparência. Curitiba: Prismas, 2016.

OLIVEIRA, M. E. de; STOLTZ, T. Teatro na escola: considerações a partir de Vygotsky. Educar em Revista, n. 36, p. 77-93, 2010.

PINHEIRO, N. M.A.; SILVEIRA, R. M. C.F.; BAZZO, W. A. Ciência, tecnologia e sociedade: a relevância do enfoque CTS para o contexto do ensino médio. Ciência \& Educação, v. 13, n. 1, p. 71-84, 2007.

REGO, T. C. Vigotsky: Uma Perspectiva Histórico-Cultural. Petrópolis, RJ: Vozes, 2014.

REIS, E. F. dos; OLIVEIRA, R. L. C. de; RIZZATTI, I. M. A trilha do Parque Ecológico Bosque dos Papagaios como espaço não-formal de aprendizagem da Organografia Vegetal. Revista Insignare Scientia, v. 2, n. 4, p. 297-313, 2019.

SCHVINGEL, C. et al. Uma experiência pedagógica em em espaços não formais de aprendizagem. Trilhas Pedagógicas, v. 6, n. 6, p. 184-195, 2016.

SILVA, M. G.; AMARAL, E. M. R. Pesquisa em ensino de biologia: características da produção acadêmica do Programa de Pós-Graduação em Ensino de Ciências da Universidade Federal Rural de Pernambuco, Brasil. Ciência \& Educação, v. 21, n. 2, p. 285-305, 2015.

SOARES, M. H. F. B. Jogos e atividades lúdicas para o ensino de química. Goiânia: Kelps, 2015.

SOARES, M. H. F. B.; GARCEZ, E.S.C. Um estudo do estado da arte sobre a utilização do lúdico em ensino de química. Revista Brasileira de Pesquisa em Educação em Ciências, v. 17, n. 1, p. 183-214, 2017.

VIGOTSKI, L. S. A Formação Social da Mente: O desenvolvimento dos processos Psicológicos Superiores. 7. ed. São Paulo, SP: Martins Fontes, 2007. 
6. ANEXO - Artigos relacionados ao tema lúdico publicados na RBPEC entre os anos de 2001 e 2018.

\begin{tabular}{|c|c|c|c|c|}
\hline \multicolumn{2}{|r|}{ RBPEC } & $\begin{array}{l}\text { Componente } \\
\text { curricular }\end{array}$ & Nível de ensino & Tipo de atividade lúdica \\
\hline 1 & V. 1, N. 3, 2001 & Física & Ensino médio & Vídeo \\
\hline 2 & V. 3, N. 1, 2003 & Química geral & Graduação & Software Dicewin \\
\hline 3 & V. 6, N. 3, 2006 & Física & Ensino fundametal & $\begin{array}{l}\text { História infantil e } \\
\text { modelagem }\end{array}$ \\
\hline 4 & V. 7, N. 1, 2007 & Física & Ensino médio & Software Modellus \\
\hline 5 & V. 8, N. 2, 2008 & Biologia & Ensino fundamental & Jogo \\
\hline 6 & V. 8, N. 3, 2008 & Educação em saúde & $\begin{array}{c}\text { Ensino médio (formação } \\
\text { de professores) }\end{array}$ & Jogo \\
\hline 7 & V. 8, N. 3, 2008 & Química & $\begin{array}{l}\text { Ensino fundamental e } \\
\text { médio (EJA) }\end{array}$ & Jogo e experimentação \\
\hline 8 & V. 10, N. 2, 2010 & Química & Ensino médio & $\begin{array}{c}\text { Experimentação, } \\
\text { modelagem }\end{array}$ \\
\hline 9 & V. 10, N. 2,2010 & Física e matemática & $\begin{array}{l}\text { Ensino fundamental e } \\
\text { médio }\end{array}$ & Brincadeira de soltar pipa \\
\hline 10 & V. 10, N. 2, 2010 & Biologia & Ensino fundamental & Jogo \\
\hline 11 & V. 11, N. 1, 2011 & $\begin{array}{l}\text { Física, matemática, } \\
\text { história, geografia e } \\
\text { conteúdos transversais }\end{array}$ & Ensino fundamental & Roleplaying game (RPG) \\
\hline 12 & V. 11, N. 1, 2011 & Biologia & Ensino médio & Jogo \\
\hline 13 & V. 11, N. 1, 2011 & Biologia & Ensino fundamental & Trilha da biodiversidade \\
\hline 14 & V. 11, N. 1,2011 & Biomecânica & Graduação & $\begin{array}{c}\text { Sistema hipermídia } \\
\text { Biomec }\end{array}$ \\
\hline 15 & V. 11, N. 1, 2011 & $\begin{array}{l}\text { Química, biologia, } \\
\text { ecologia e artes }\end{array}$ & Ensino médio & $\begin{array}{c}\text { Visita a galeria de arte e } \\
\text { modelagem }\end{array}$ \\
\hline 16 & V. 11, N. 3, 2011 & Biologia & Ensino médio & Trilha e experimentação \\
\hline 17 & V. 13, N. 2, 2013 & Física & Ensino médio & $\begin{array}{c}\text { Visita à 'Casa Maluca' da } \\
\text { USP }\end{array}$ \\
\hline 18 & V. 14, N. 1, 2014 & Primeiros socorros & Ensino técnico & $\begin{array}{c}\text { Objeto virtual de } \\
\text { aprendizagem (OVA) }\end{array}$ \\
\hline 19 & V. 14, N. 1, 2014 & Biologia e química & Ensino médio (EJA) & Vídeo e modelagem \\
\hline 20 & V. 14, N. 2, 2014 & Química & Ensino médio & Vídeo e experimentação \\
\hline 21 & V. 14, N. 3, 2014 & Química & $\begin{array}{c}\text { Educação infantil, ensino } \\
\text { fundamental, médio e } \\
\text { graduação }\end{array}$ & Teatro e experimentação \\
\hline 22 & V. 15, N. 2,2015 & $\begin{array}{l}\text { Biologia e conteúdos } \\
\text { transversais }\end{array}$ & Ensino fundamental & Jogo \\
\hline 23 & V. 15, N. 3, 2015 & Biologia e filosofia & Ensino médio & Filme, vídeo e mural \\
\hline 24 & V. 16, N. 1,2016 & Física & Ensino médio e técnico & $\begin{array}{l}\text { Microportal } S_{c i} i_{2} \text { mobile de } \\
\text { recursos multimídia }\end{array}$ \\
\hline 25 & V. 17, N. 1,2017 & Não se aplica ${ }^{2}$ & Não se aplica & Não se aplica \\
\hline 26 & V. 18, N. 1,2018 & Não se aplica ${ }^{2}$ & Não se aplica & Não se aplica \\
\hline 27 & V. 18, N. 3, 2018 & Biologia & Ensino médio & Visita a museu de ciências \\
\hline
\end{tabular}

Fonte: elaborado pelas autoras.

2 O artigo apresenta uma revisão da literatura não havendo destaque para um específico componente curricular, nível de ensino ou tipo de atividade lúdica. 